\title{
Utility, Maximizing, and the Satisficing Concept: A Historical Approach at Reconciliation
}

\author{
David D. Van Fleet \\ Morrison School of Agribusiness, W. P. Carey School of Business \\ Arizona State University
}

\begin{abstract}
Author Note
I have no conflicts of interest to disclose.

Correspondence concerning this article should be addressed to David Van Fleet, $4849 \mathrm{E}$. Altadena Avenue, Scottsdale, AZ 95254.

Email: ddvf@asu.edu
\end{abstract}




\begin{abstract}
Utility is used in both economic and business theories of decision-making. The tradition utility approach using maximizing concepts seems at odds with the concept of satisficing behavior. The relation between utility and the satisficing concept is suggested to be that satisficing refers to a process of adaptive behavior by which an economic unit strives to attain a satisfactory level of utility for higher ranking objectives before turning to lower-ranking objectives. There is no necessary inconsistency between utility and satisficing, although the assumption of maximization must be replaced, in positive analysis, by that of satisficing since the scope referred to by each of the concepts, positive and normative, is quite different. This paper uses historical material to develop a model, which is then used to analyze those relations.
\end{abstract}

Keywords: utility, satisficing behavior, model 


\section{Utility, Maximizing, and the Satisficing Concept: A Historical Approach at Reconciliation}

Can the traditional utility approach of economics lead to a reconciliation between maximizing and satisficing? Is there any relationship between them (Kapteyn, Wansbeek, \& Buyze, 1979)? Employing historical material, this paper briefly reviews those concepts and suggests answers to such questions.

\section{Definitions}

Any effort to answer such questions involves the interdisciplinary field of behavioral science (Berelson \& Steiner, 1964; Kolasa, 1969). Much of the data of economics is obtained from the behavior of individuals and organizations (Viner, 1917) and is, therefore, part of behavioral science. Yet, some readers may not be familiar with the terms used in behavioral science. For that reason, some definitions need to be clearly identified and understood.

Many of the terms utilized in the behavioral sciences are those of psychology, and the definitions from that field shall be adhered to (English \& English, 1958). In addition, specific definitions of satisficing and utility need to be understood.

Satisficing

The term satisficing was developed by Simon to refer to what psychologists normally call "satisfying," except that Simon uses it to mean the satisfaction of economic goals implying behavior that may well not be maximizing behavior (Simon, 1959). A decision-maker in an economic organization may not attempt to maximize any particular variable; but, rather, may simply want to earn a return that is satisfactory (Simon, 1955 and 1960). Thus, the following definition:

Satisficing (adjective). Achieving a satisfactory level of goal accomplishment. That level is usually less than maximum, implying non-maximizing behavior on the part of the economic unit.

\section{Utility}

Utility has been used to refer to many concepts, so it is necessary to specify how it is to be used here. A simple definition is "the quality or property of being useful: usefulness" or "the power to satisfy the needs or wants of humanity" (Webster's, 1962, p. 2013). These general definitions are inadequate for the purpose here. Perusing the works of economists suggests that too frequently, it is used without any definition. However, some texts have provided definitions (see, for example, Bye, 1927, p. 15; Boulding, 1948, p. 614; Henderson \& Quandt, 1958, pp. 620; Samuelson, 1967, p. 417; Fishburn, 1970). Synthesizing these, then, the definition to be used here is:

Utility (noun). The power or ability as perceived by an economic unit to gratify wants, needs, or desires. The perceived product or end result of such gratification.

These two definitions, then, are the prominent ones employed in the following analysis. 


\section{Analysis}

Before embarking on the analysis of the similarities, dissimilarities, and the eventual relationship between utility, maximizing, and the satisficing concept, a brief review of the fundamentals of utility and satisficing is in order.

\section{Utility}

Modern utility analysis developed from the work of several economists, including Bentham, Walras, Marshall, and Pareto, who paved the way (Stigler, 1950a \& 1950b). Utility theory begins with the assumption that a consumer derives utility, as defined earlier, from various activities. Then cardinal or ordinal schedules are developed and used to study behavior. This presupposes rational action on the part of the economic unit. The rational or "economic man" idea is one of the aspects of utility analysis that behavioralists have criticized (Leibenstein, 1976). To appreciate the criticism, one must first know what is really meant by the "rational man."

Rational man knows his alternatives, the outcomes of each of those, his own "preference ordering" of those, and then merely selects the best from among the set of alternatives (Friedman, 1940; Friedman \& Savage, 1948; March \& Simon, 1958). Another assumption in utility analysis is "optimality." Optimality occurs when all alternatives are compared by a set of criteria, and one alternative emerges as preferable (March \& Simon, 1958, p. 140). Based on these assumptions, the usual total utility curve is as shown in Figure 1

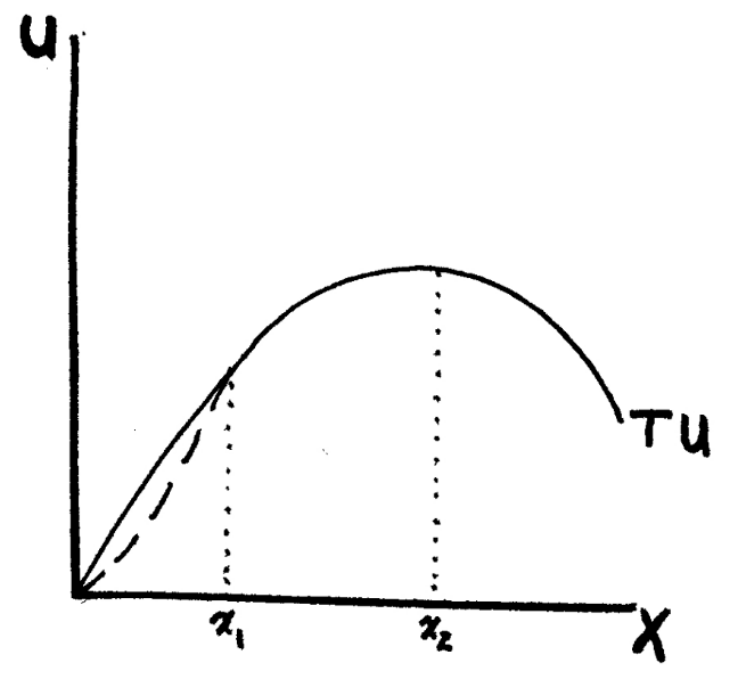

Figure 1

The solid line is the total utility when marginal utility from 0 to $\mathrm{X}_{2}$ is diminishing. If the marginal utility from 0 to $X_{2}$ is increasing, the total utility curve may appear as the dashed line. The rational man would then deal with $\mathrm{X}$ until he reached his optimal situation, which in this case is the maximum at the point $\mathrm{X}_{1}$. 
As an in-depth discussion of utility is not needed here, only these few aspects of the analysis are indicated so that when comparisons are made, the reader will have the concept more clearly in mind. Many criticisms have been made of utility theory, particularly the assumptions of rationality, maximizing, and optimality. These criticisms plus observations of behavior led March and Simon to their analysis (March \& Simon, 1958).

\section{Satisficing}

The concept of rationality employed by March and Simon involves the following (March \& Simon, 1958, p. 176):

1. The existence of certain requirements or criteria which are subject to gradual change over time

2. If one or more of these criteria are not met, action will be initiated to alleviate the situation

3. Change involves not only choice but also a process of initiation or search

4. Complicated interrelations are largely absent; hence action is based primarily on demands upon scarce organizational resources.

In the search for courses of action, the alternatives are tested in sequence; and when one is found which is satisfactory, it is used as a solution, and search stops. If however, search does not yield any results, then the criteria are relaxed so that a satisfactory solution may be found(March \& Simon, 1958, pp. 179-180). Note that "satisfactory" is used rather than "optimal."

When is an alternative satisfactory? An alternative is satisfactory when it meets or exceeds minimal criteria levels (March \& Simon, 1958, p. 140). An alternative is satisfactory if it is "good enough." The distinction between optimal and satisfactory is the difference between finding the sharpest needle in a haystack and finding one sharp enough with which to sew (March \& Simon, 1958, p. 141; see also Charnes \& Cooper, 1962). This, then, is satisficing (Baumol \& Simon, 1963).

In summary, then, satisficing involves several assumptions, as does utility theory, but those assumptions are not as rigid and may be more realistic.

\section{Relation Between Concepts}

As shown in Figure 2, a simple way to view a possible relationship between utility and satisficing is to rationalize a lumpy total utility curve and argue that the lower level or mode is the satisficing level. The lighter line connecting the two modes may lead one further to argue in favor of a "utility plateau." In that situation, the lower level would be non-maximum; but the lower level is also not truly a satisficing level. 


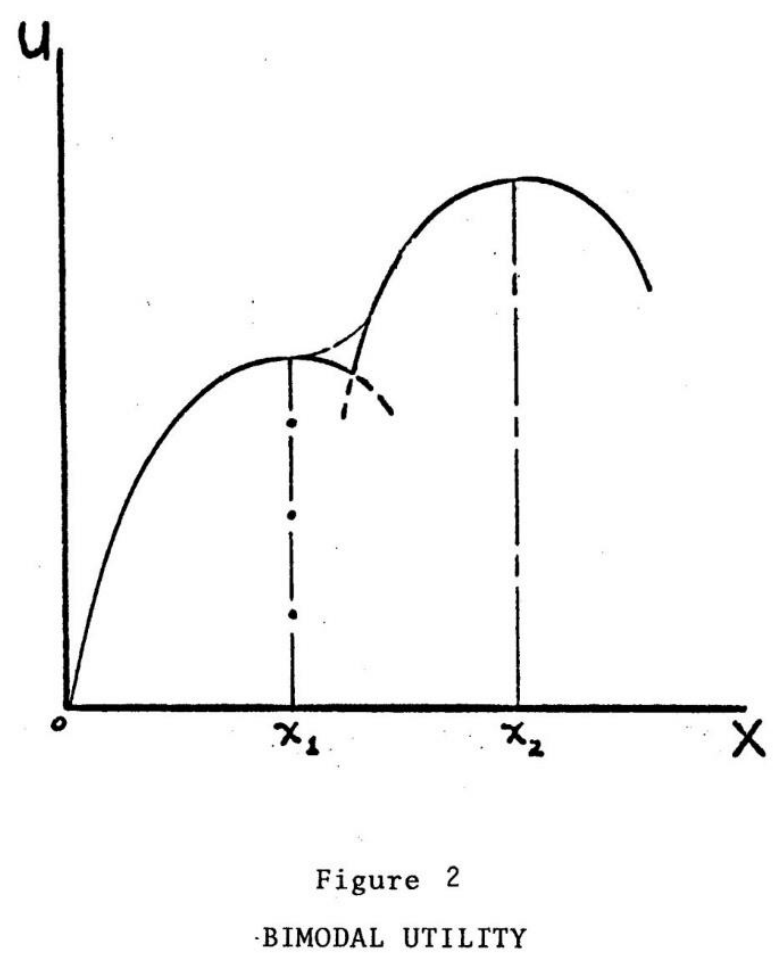

Auspitz and Lieben (Hawey, 1960) developed multimodal utility curves called "Lebensweise," which represent changes in perceived utility for individuals over time. The "Lebensweise" was thought to change whenever conditions aside from the quantity of the good in question changed. Multiobjective approaches also exist (Wierzbicki, 1978). These ways of rationalizing satisficing in terms of classical utility are interesting but inadequate. The satisficing concept is a level of utility lower than maximum, but there is more to the concept than just that.

\section{A Monopoly Approach}

A more sophisticated reconciliation could be developed along the lines proffered by Olsen (1973). Assume a monopoly situation in which the firm can by normal ( 8 hour/day) operation satisfy only a part of the total market demand. Using emergency operations (24 hour/day, 7 day/week), the firm can meet the total demand. Further, assume that the firm has a goal of staying in business so long as it can make a profit without much government interference. This goal of the firm could be broken into three parts: producing some quantity, obtaining a profit, and keeping government interference low. The only other assumption needed is that no other firm can enter the market, perhaps due to an extremely large initial investment. The utility surfaces of this goal can be shown diagrammatically in the traditional manner if and only if a net utility of profit and a net utility of quantity relationship can be developed that includes the effect of government interference.

\section{Net Utility of Profit Given Government}

The development of the net utility curve of profit, given the effects of government intervention, involves first defining the utility surfaces for profit and for government. The utility curve for profit may be an increasing function where the specific shape is assumed to be the same 
for any level of government intervention or interference. However, the higher the level of government interference, the lower the curve. The decreasing height of the profit utility curve with an increase in government interference is based on businesses ' perception of only the utility of profits as government interference changes and does not take into account the utility of government interference. Note that this phase of the analysis is on a relatively high level of abstraction in order to develop the more realistic, or at least operational, net utility curve. The portion of this development is shown as Surface A in Figure 3.

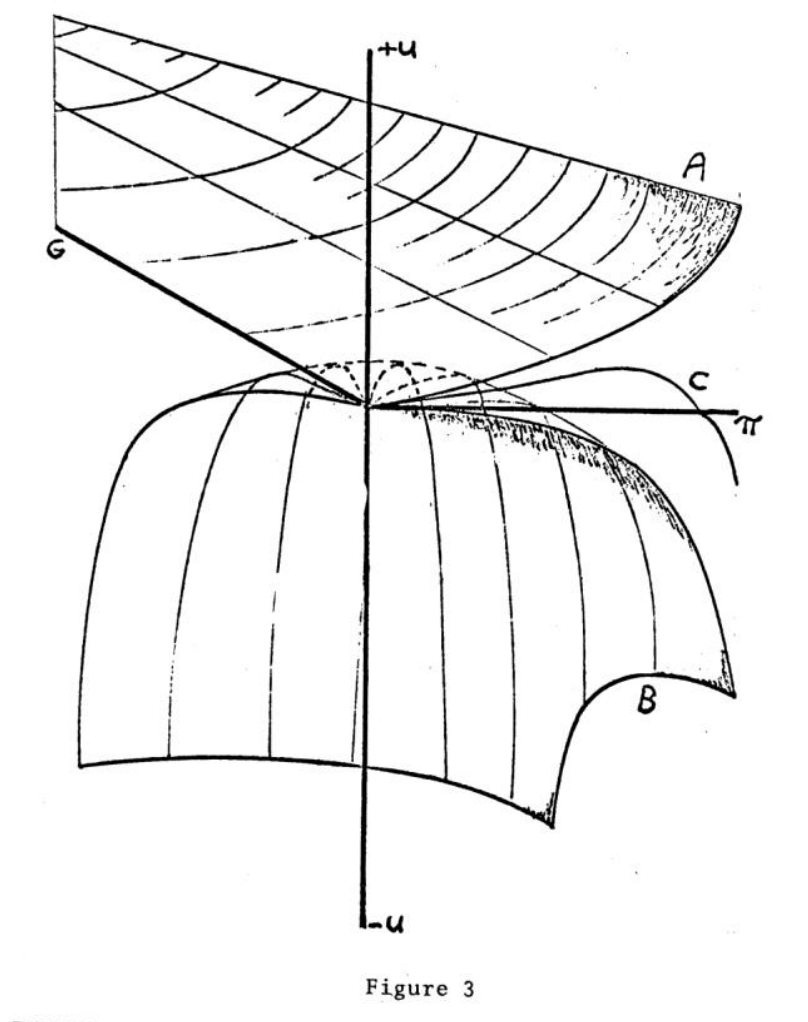

DEVELOPMENT OF THE NET. UTILITY OF P.ROFIT GIVEN GOVERNMENT

The utility curve for government in profit matters may be an ever decreasing function. This curve represents the utility, or actually the disutility, to the businessman, in matters of profit, of government interference. The shape of this curve is assumed to be the same for any level of profit, but the higher the level of profit, the lower the curve or the greater the disutility. The decreasing height of the government interference disutility curve with increases in profit is based upon the businessman's perception of on1y the disutility of government interference as profits change and does not take into account the utility of profit. This portion of the development is shown as Surface B in Figure 3.

By algebraically adding the utility of profit to the disutility of government, a new utility or a net utility of profit given government can be derived. This is a relevant utility surface for the businessman. The section of the net utility surface, which intersects the profit utility plane, is shown as line $\mathrm{C}$ in Figure 3.

\section{Net Utility of Quantity Given Government}


The development of a net utility of quantity given government is very similar to that of the development of the net utility of profit given government. The utility of quantity has a shape similar to that of total utility shown earlier in Figure 1. The utility is greatest at the normal operating level of quantity, not at the quantity which maximizes profits since the concern here is on $1 y$ with quantity and not profits. Beyond the maximum point, the utility falls off until at the point of maximum physical production, assuming no increase in plant size, the total utility, $\mathrm{TU}_{\mathrm{Q}}$, is zero. Using the same reasoning as with profit, the height of this curve decreases with increasing government interference. This surface is shown as Surface A in Figure 4.

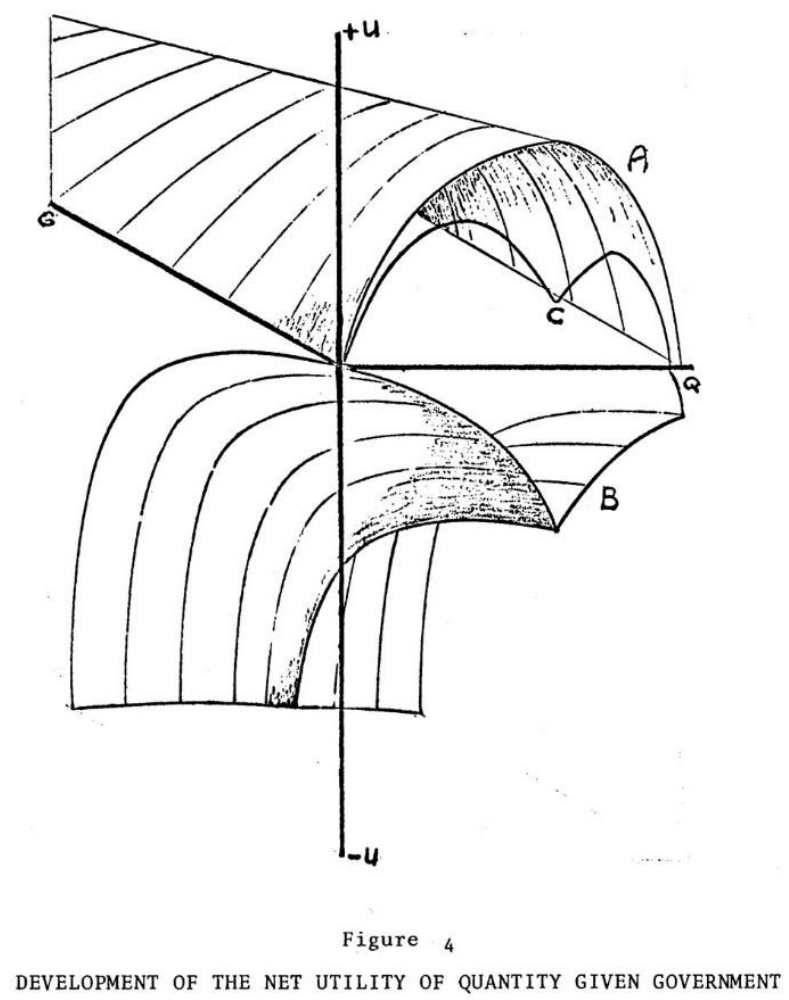

The utility curve of government interference is the same as it was for profits, except that it is not ever-increasing as quantity increases. In the case of quantity, government interference is greatest around the point of normal operations on the assumption that market demand is not being met; however, as the monopolist strives to meet the total market demand, the perceived government interference decreases (although it never becomes zero) as a result of a change in management philosophy. This change in philosophy might occur because of the businessman's merely "becoming accustomed" to the role of government. The disutility surface of government in matters of quantity is then shown as Surface B in Figure 4.

Once again, by algebraically adding the utility of quantity and the disutility of government interference, a new utility or a net utility of quantity given government is derived. The relevant portion of this surface is shown as line $\mathrm{C}$ in Figure 4.

\section{Net Indifference}


Following traditional approaches, the next step is to develop the indifference map of profit and quantity or, in this case, the net indifference map of profit and quantity given government interference. This is accomplished by using the net utility curves, as shown in Figures 3 and 4 in a new diagram, Figure 5. In the development of the net utility of profit given government and the net utility of quantity given government curves in Figure 3 and Figure 4 above, profit and government were conflicting goals, as were quantity and government. In the present development, the net utility of profit given government and the net utility of quantity given government are complimentary goals. The surface generated by this analysis is then a "mountain range" with two peaks. This need cause no new problem for a solution; however since methods for solving such problems already exist (compare with Weintraub, 1964).

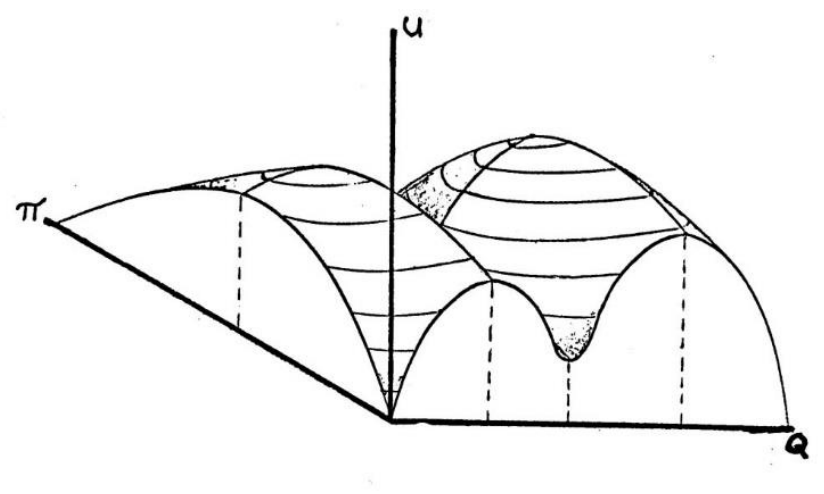

Figure 5

UTILITY SURFACE OF PROFIT AND QUANTITY

If in Figure 4, it is assumed that the slope of the line generated by the intersection of Surface B with the quantity-utility plane is less (at any given $U$ ) before the minimum than after the minimum, then the height of the second mode of the net utility of quantity given government will be greater than the first mode of that curve. Then, if the second mode is greater than the first, the "mountain range" developed in Figure 5 will have a second mode of the net utility of quantity given government, which is higher in measures of total utility than the first peak.

This being the case, then, the contour, equal utility, or indifference lines will be closer together for the higher peak than the lower, as is illustrated in Figure 6. Note that Figure 6 is only representative of the type of indifference map, which could come from a form as in Figure 5 and not the exact map of Figure 5. 


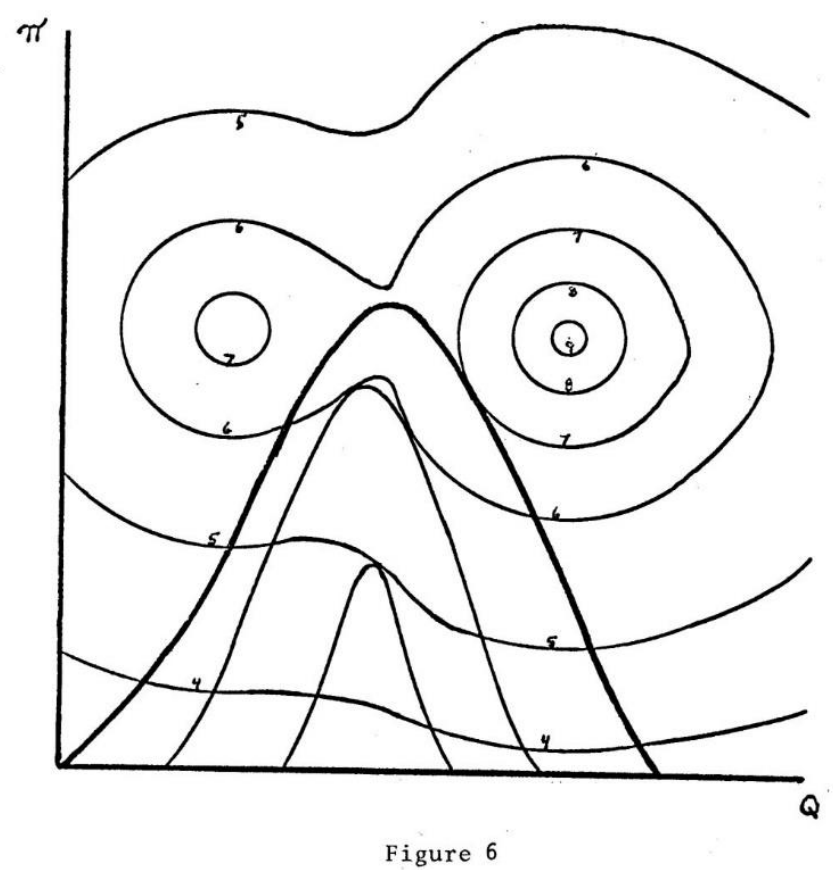

THE PROFIT AND QUANTITY INDIFFERENCE MAP AND POSSIBLE TOTAL PROFIT CURVES

Shown along with the net indifference map in Figure 6 are several possible total profit (bell-shaped) curves (compare with Weintraub, 1964, pp. 190-192). From just the few shown, it can be seen that depending upon the shape of the total profit curve, the monopolist may produce at less than, more than, or equal to maximum profits; and that in certain cases, he may be indifferent as to producing two quantities each of which will yield the same profit. Note, however, that the maximum profit tangency position is only a very limited special case and not necessarily the normal one.

Since the net indifference map was derived using all amounts of production, the profit curve shown by the heavy line is probably more realistic for this diagram. Note that this curve indicates that the monopolist will produce a quantity greater than that which will maximize profits (compare with Scherer, 1970 and Baumol, 1959 and 1961).

Are these levels of profit and quantity satisficing levels? If change occurs in this analysis over time and individuals and if it is assumed that a monopolist behaves "as if" this analysis were valid and if the utilities involved are primarily expected utilities under uncertainty, then this analysis will describe the results of a monopolist's behavior similar to those results described by the satisficing analysis.

\section{The Big Question}

The big question still remaining is, "Can the concepts of utility maximization and satisficing be reconciled?" The answer is yes. How? Not merely by sophistry (Simon, 1959); but rather by one simple statement: in normative analysis, the use of the concept of modified rationality and of maximizing expected utility is more useful; in positive analysis, the use of the 
concept of purposive rather than rational behavior and of satisficing is more useful. This is due to the differences in the scope of normative versus positive economics.

If man "ought" to be satisfied with less than optimum performance, then the drive to invent, innovate, and seek a better situation would be greatly tempered even though the satisficing concept recognizes that gradual increases in aspiration levels may occur. Also, in describing "what is," it is extremely unscientific to turn our backs on the psychological evidence in support of theories of adaptive behavior and satisficing theories (Simon, 1959; see also Barnard, 1938, Cartwright \& Zander, 1960, Latane et al., 1963 especially pp. 97-106 and pp. 114-115).

Basing public policy measures solely on normative economics may be a grave error. Business firms may be operating in such a way as to negate or at least severely reduce the impact of many policy measures (Baumol \& Simon, 1963; Cyert \& March, 1955). If so, then policy considerations must take into account both positive and normative aspects of economics. But in line with the scope of this analysis, it can be stated, in conclusion, that utility analysis may be useful in positive economics to the extent that in using it, the analyst recognizes adaptive behavior, multiple and conflicting goals, uncertainty, and the satisficing concept. The relationship between satisficing and utility is, then, that satisficing is achieving a satisfactory level of total utility for the commodities or goals perceived by the economic organism.

\section{Conclusions}

The utility function facing the businessman contains a large number of variables in a complicated set of relationships. These variables may be in additive, ratio, quotient, or any one of a number of possible relationships to each other. In referring to business goals, these variables may well be conflicting, in that as the businessman increases profit to make owners happy, government interference may increase, or be interacting, in that, as profit increases, pressure from stockholders decreases.

Since the above situation does exist, the businessman cannot maximize his total utility by simply maximizing each and every partial variable. This means that total utility is not maximized by equating the marginal utilities of each separate situation. However, there are limits on human ability (and computer ability as well) to retain and evaluate all of the variables in the total utility function simultaneously. Thus, the businessman must segment the total utility function into subsets and deal with each subset or variables within each subset separately. But he cannot maximize these subsets because he does not know whether to do so will even tend towards the maximum of the total utility function. This is not a "real" dilemma to the businessman, however, since he must operationally deal with the subsets and the variables individually.

In addition, perfect knowledge does not exist; therefore, the businessman is aware that if he is to maximize any of the elements of his increasingly complex situation, he must obtain information from the system in order to reduce the uncertainty regarding not only the outcome of the specific events but also the relationships between the variables in his utility function. However, he may not maximize information since there may be an optimal amount of 
information that is less than the maximum. This diminishing returns to information is a result of the increasing redundancy in an information system as the total amount of information increases. Thus, the conclusions of this analysis are that people in business act as if they: 1) satisfice--since they do not know whether to maximize the variables and/or subsets, they will merely establish levels which they think will lead to that overall maximum (these are their aspiration levels) and to the extent that they achieve or fail in the striving for these goals they will behave in accordance with the adaptive mechanism described by Simon (1972, pp. 161-176); 2) be conservative--this is merely one manifestation of the satisficing procedure; and 3) attempt to assimilate information about their system--since they need this information in order to achieve any possible maximum utility (this information may well be in the form of collusion or information about competitor's behavior).

The process of such satisficing behavior may not take place by a simple ranking of goals. Instead, due to the limitations of individuals to effectively retain several different bits of information simultaneously, the process may involve:

1. Arranging the goals into sets

2. Ranking the sets according to their perceived importance to the individual

3. Then starting from the highest ranked set, rank the goals within the set, and

4. Proceeding in the manner described by March and Simon earlier, attain satisficing levels for each goal.

It should be pointed out that the values of the weighted marginal expected utilities will not necessarily be equated since that theorem is based on the maximizing assumption, which no longer is applicable.

In addition, the satisficing procedure should be directly modified to take into account "pressure." For just as the perceived goals of the economic unit may be conflicting or complementary, so pressure from various endogenous and exogenous groups or economic units can also be against or for the attainment of those goals. The effect of such pressures may cause the goals to be changed in some way, the aspiration levels associated with those goals to be lowered or raised, or the levels of satisfaction to be varied in some manner. If the pressures are all in an upward direction, that is, toward maximizing, then maximizing may be a relatively realistic abstraction. However, there is no necessary reason for all pressures or even most pressure, which is exerted on the decision-maker, to be in that direction.

Thus, the relation between utility and the satisficing concept is that satisficing refers to a process of adaptive behavior in which an economic organism strives for the attainment of a satisfactory level of utility for certain more important or higher-ranking goals before turning its attention to second-ranking goals, third-ranking goals, and so on. Thus, there is no necessary inconsistency between utility and satisficing, although the assumption of maximization of utility must be replaced, in positive economics, by that of satisficing utility since the scope referred to by each of the concepts, positive and normative, is different. 


\section{References}

Barnard, C. I. (1938). The functions of the executive. Harvard University Press.

Baumol, W. J., \& Simon, H. A. (1963). Proceedings of a symposium on Decision Theory.

Division of Research, College of Business Administration, Ohio University, Athens, Ohio.

Baumol, W. J. (1959). Business behavior, value and growth. The Macmillan Company.

Baumol, W. J. (1961). Economic theory and operations analysis. Prentice-Hall.

Berelson, B., \& Steiner, G. A. (1964). Human behavior. Harcourt, Brace and World.

Boulding, K. E. (1948). Economic analysis. Harper \& Bros.

Bye, R. T. (1927). Principles of economics. Alfred A. Knopf.

Carter, W. H., \& Snavely. W. P. (1961). Intermediate economic analysis. McGraw-Hill Book Company.

Cartwright, D., \& Zander, A. (1960). Group dynamics. Row, Peterson and Company.

Charnes, A., \& Cooper, W. W. (1962). Deterministic equivalents for optimizing and satisficing under chance constraints. Operations Research, 11(1), 18-39.

Cyert, R. M., \& March, J. G. (1955). Organizational structure and pricing behavior in an oligopolistic market. American Economic Review, 45(1), 129-39.

Duncan, A. J. (1959). Quality control and industrial statistics. Richard D. Irwin.

English, H. B., \& English, A. C. (1958). A comprehensive dictionary of psychological and psychoanalytical terms. Longmans Green and Company.

Fishburn, P. C. (1970). Utility theory for decision making. John Wiley.

Friedman, M., \& Savage, L. J. (1948). The utility analysis of choices involving risk. Journal of Political Economy, 56(4), 279-304.

Friedman, M. (1953). Essays in positive economics. University of Chicago Press.

Hawey, R. S. (1960). The rise of the marginal utility school, 1870-1889. University of Kansas Press.

Henderson, J. M., \& Quandt, R. E. (1959). Microeconomic theory. McGraw-Hill Book Company.

Kapteyn, A., Wansbeek, T., \& Buyze, J. (1979). Maximizing or satisficing. The Review of Economics and Statistics, 61(4), 549-563.

Kolasa, B. J. (1959). Introduction to behavioral science for business. John Wiley.

Latane, H. A., et al. (1963). The social science of organizations. Prentice-Hall, Inc.

Leftwich, R. H. (1966). The price system and resource allocation ( $3^{\text {rd }}$ ed.). Holt, Rinehart and Winston.

Leibenstein, H. (1976). Beyond economic man. Harvard University Press.

March, J. G., \& Simon, H. A. (1958). Organizations. John Wiley \& Sons.

Marshall, A. (1920). Principles of economics ( $8^{\text {th }}$ ed.). Macmillan and Co.

McConnell, G. R. (1963). Economics: Principles, problems, and policies. McGraw-Hill Book Company.

McKenna, J. P. (1958). Intermediate economic theory. The Dryden Press.

Robbins, L. C. (1940). An essay on the nature and significance of economic science. Macmillan and Company.

Samuelson, P. A. (1967) Economics: An introductory analysis ( $7^{\text {th }}$ ed.). McGraw Hill.

Scherer, F. M. (1970). Industrial market structure and economic performance. Rand McNally.

Schumpeter, J. A. (1950). Capitalism, socialism, and democracy. Harper \& Bros.

Copyright (C) Institute of Behavioral and Applied Management. All Rights Reserved. 
Simon, H. A. (1959). Theories of decision-making in economics and behavioral science. American Economic Review, 49(3), 253-83.

Simon, H. A. (1955). A behavioral model of rational choice. Quarterly Journal of Economics, 69, 99-118.

Simon, H. A. (1972). Theories of bounded rationality. In C. B. McGuire, and R. Radner (eds.), Decision and organization (pp. 161-176). North-Holland Publishing Company.

Simon, H. A. (1960). The new science of management decision. Harper G Bros.

Stigler, G. J. (1950a). The development of utility theory I. Journal of Political Economy, 58(4), 507-27.

Stigler, G. J. (1950b). The development of utility theory II. Journal of Political Economy, 58(5), 573-96.

Viner, Jacob. (1917). Some problems of logical method in political economy. Journal of Political Economy, 25(3), 236-68.

von Neumann, J., \& Morgenstern, O. (1953). Theory of games and economic behavior. Princeton University Press.

Webster's New Twentieth Century Dictionary. (1962). The World Publishing Company.

Weintraub, S. (1964). Intermediate price theory. Chilton Book Publishers.

Wierzbicki, A. P. (1978). On the use of penalty functions in multiobjective optimization. Proceedings of the International Symposium on Operations Research, Mannheim.

Wilde, D. J. (1964). Optimum seeking methods. Prentice-Hall. 